\title{
Rate of Soil Contamination by Soil Transmitted Helminths in Relation to the Awareness Status of Pupils in Primary Schools of Penka-Michel, West-Cameroon
}

\author{
Atiokeng Tatang Rostand Joël ${ }^{1,}$ *, Yondo Jeannette ${ }^{2}$, Tsila Henri Gabriel ${ }^{1}$, \\ Nguemfo Tchankugni Arlette ${ }^{1}$, Nkouayep Vanessa Rosine ${ }^{1}$, Mpoame Mbida ${ }^{1}$ \\ ${ }^{1}$ Research Unit of Biology and Applied Ecology, Department of Animal Biology, Faculty of Science, University of Dschang, Dschang, \\ Cameroon \\ ${ }^{2}$ Department of Biological Sciences, Faculty of Medicine and Pharmaceutical Sciences, University of Dschang, Dschang, Cameroon
}

\section{Email address:}

rostandatiokeng@yahoo.fr (A. T. R. Joël), yondojanet@yahoo.fr (Y. Jeannette), tsilahenrigabriel@gmail.com (T. H. Gabriel), arlettetyna@yahoo.com (N. T. Arlette), vanessa.nkouayep@gmail.com (N. V. Rosine), mpoamembida@yahoo.fr (M. Mbida)

${ }^{*}$ Corresponding author

\section{To cite this article:}

Atiokeng Tatang Rostand Joël, Yondo Jeannette, Tsila Henri Gabriel, Nguemfo Tchankugni Arlette, Nkouayep Vanessa Rosine, Mpoame Mbida. Rate of Soil Contamination by Soil Transmitted Helminths in Relation to the Awareness Status of Pupils in Primary Schools of Penka-Michel, West-Cameroon. Journal of Health and Environmental Research. Vol. 7, No. 2, 2021, pp. 112-121.

doi: $10.11648 /$ j.jher.20210702.15

Received: March 17, 2021; Accepted: April 2, 2021; Published: May 14, 2021

\begin{abstract}
Background: Soil transmitted helminth (STH) infections disproportionately affect poor populations in tropical and subtropical parts of the world. They contaminate soil and pupils are mostly at risk of these infections due to their soil related habits. Aims: to assess pupils' knowledge, attitude and practice in relation to the rate of soil contamination in public primary schools. Methods: Structured questionnaires were administered to 729 consenting participants to obtain information on their awareness status of STH infections. A total of 552 soil samples were collected around toilets, classrooms backyards and playground in 23 public schools randomly selected in Penka-Michel subdivision and examined for the presence of STH eggs using the sucrose flotation method. Results: up to $80 \%$ of respondents do not actually know how to avoid getting infected with worms. About $50 \%$ of pupils do not actually wash their hands after defecating or wash their fruits/vegetables before eating. Pupil's nails were mostly untrimmed (74.1\%). $77.1 \%$ declared they always defecate out of the toilets when they are in school. Out of 552 soil samples examined, 97 (17.6\%) were contaminated by Ascaris sp, Trichuris sp, Toxocara sp, Capillaria sp, Cooperia sp, hokworms and Nematodirus sp. Soil from around toilets were significantly more contaminated with Ascaris sp and Trichuris sp eggs. Soil contamination was also significantly associated with absence of water during class hours, unhygienic conditions of toilets, and lack of school perimeter fence. Overall $65 \%$ of schools selected showed a low level of hygiene. Conclusion: Pupils of these schools played a major role in the contamination of their environment. Therefore, in order to prevent the STHs transmission cycles in school environment and possibly in pupils, it is necessary to develop specific sustainable intervention programs.
\end{abstract}

Keywords: Soil Transmitted Helminth, Pupils, Awareness, Soil Contamination, Penka-Michel

\section{Introduction}

Soil is a potential source of human diseases caused by many helminth parasites. Soil-Transmitted Helminth (STH) infections are among the most prevalent of chronic human infections worldwide and their distribution is closely related to climate and soil characteristics [1]. Moreover, higher prevalences are found in tropical and sub-tropical regions, especially in developing countries where their persistence is associated to poverty, lack of potable water, inadequate, or inexistent sanitary facilities, poor hygiene, and inefficient health services [2-4]. It is estimated that, more than 2 billion people, (24\%) of the world's population are infected by STH such as Ascaris lumbricoides, hookworms, and Trichuris 
trichiura [5]. Epidemiologically, there is no target age with STH infection, but due to their frequent playing with soil, walking barefoot, poor health, or nutritional status, and geophagic habits coupled with a low level of awareness, the highest rates mostly occur among school-age children living in rural areas $[6,7]$. Chronic infections have insidious effects on their growth, intellectual development, and on their school performance, thus increase their vulnerability to other disease. Heavy infections on the other hand may result in serious clinical disease [8]. In addition to the STHs pledged to humans, many other STHs species of domestic and wild animals' origin are now reported to be emerging STH parasitic infectious agent. These include: Ancylostoma caninum, Ancylostoma braziliense, Ascaris suum, Strongyloides stercoralis, Toxocara canis, and Trichuris vulpis [9]. Infection with these parasites could be of public health concern [10]. For instance in humans, A. caninum infection may leads to eosinophilic enteritis while $A$. braziliense and $T$. canis can cause cutaneous larva migrans without intestinal infection [11, 12]. These parasites are under-diagnosed due to sundry reasons such as the fact that medical personnel are largely unfamiliar with the identity of such parasites [13]. Although zoonotic and human STH infections symptoms often present very similar clinical pictures, they sometimes require different diagnostic and treatment approaches [14].

Soil plays a crucial role in the life cycle of STH species. Before becoming infective, the ova need to undergo further development through incubation in a warm and moist soil and can be viable in such conditions for several years. Indiscriminate disposal of human and animal faeces are the main sources of soil contamination by STH eggs $[15,16]$. This has been confirmed in Philippines, Kenya, Ethiopia, Vietnam, South Africa and Nigeria [17-19].

Improvement in child health and education are key targets in many international development programs, but relatively little is known about the multiple health and educational benefits of integrating different school-based health interventions [20]. In Cameroon, especially in rural area, many public schools lack functional toilet facilities and when they exist, they are mostly non maintained latrine or pit-hole toilets. Due to the high number of pupils in these schools, coupled with lack or few toilet facilities, some pupils defecate around classrooms, around toilets, or in the bushes surrounding the schools. Also, most of these schools lack drinkable water. Focusing on this, there is evidence of fecal environmental contamination which is obviously the way through which pupils may get STHs infections in schools. Based on epidemiological findings, Cameroon adopted in 2004 a strategic plan for the control of STHs and since 2007, routine annual Mass Drug Administration (MDA) has been implemented nationwide to both enrolled and non-enrolled school aged children in order to reduce prevalence and associated morbidities [21]. But soil contamination by STH eggs or larvae in school environments is understudied. This study was therefore designed to assess pupil's knowledge, attitude, and practices with respect to rate of soil contamination in selected primary schools of Penka-Michel subdivision, Western-Cameroon in order to highlight predicting factors associated to soil contamination in school environment and guide intervention programs aimed at limiting risk of infection in pupils.

\section{Material and Methods}

\subsection{Study Location and Sampling Sites}

This cross-sectional survey was carried out in PenkaMichel Subdivision of the Menoua Division, West Region of Cameroon (Figure 1). Penka-Michel is located between latitude $21.52,5^{\circ}$ and $31.41,5^{\circ}$ north of the equator and longitude $7.39,10^{\circ}$ and $20,10^{\circ}$ East of the GreenWich Meridian, at an altitude of about $1500 \mathrm{~m}$ above sea level. The locality experiences two distinct seasons: a short dry (November to March) and a long rainy season (March to November). The highest rainfall registered in a year could reach $345.1 \mathrm{~mm}$ and the thermal amplitude between the hottest month of the year (March: $21.5^{\circ} \mathrm{C}$ ) and the coldest (August: $18.9^{\circ} \mathrm{C}$ ) is $2.6^{\circ} \mathrm{C}$. Penka-Michel is a rural area made up of four villages (Balessing, Bamendou, Baloum and Bansoa) with an estimated population of about 124880 people of which 'Bamilikés' constitute more than $90 \%$ of inhabitants [22]. Penka-Michel has 64 Public and 23 private primary schools.

\subsection{Study Design}

Twenty-three (23) government primary schools out of the sixty-four (64) found in Penka-Michel subdivision were randomly selected for this study. This was done by writing the name of each school with respect to their village on a separate piece of paper, then placed in four boxes (representing the 4 villages) and thoroughly mixed before selection by blindly picking the pieces of paper. As result 23 schools where selected: 6/23 in Bamendou, 6/23 in Bansoa, $6 / 11$ in Balessing and 5/7 in Baloum (Figure 1).

\subsection{Ethical Approval}

Permission to carry out the investigation was granted by West regional delegate of public health, public health officers of Penka-Michel district and authorities in charge of basic education in Penka-Michel. Voluntary participation and withdrawal from the study at any time without repercussion were ensured. All data/information on participants from the completed questionnaire were kept confidential to prevent undue access by any third party.

\subsection{Administration of Questionnaire}

A structured questionnaire was administered to each participating pupil aged from 4 to 14 years. The questionnaire was designed to collect information on personal bio-data on their attitudes and practices, on characteristics of their homes as well as their perception and knowledge on soil transmitted infections. Especially, young 
pupils of 4 to 7 years old and others were assisted by their brothers of other classes, by their teachers or by the head of school in completing the questionnaire and where necessary, questions were translated in dialect for better understanding.

The sample size of participants for the study was calculated using prevalence $52.8 \%$ of STH reported by Tchuem Tchuenté et al. [23] among pupils in southern Cameroon, applying the following formula:
Where; $n=$ the expected sample size, $\mathrm{p}=$ prevalence of STH infection in school children from previous studies $(\mathrm{P}=0.528)$, $\mathrm{d}=5 \%$ (margin of error) and $\mathrm{Z}_{1-\propto / 2}=1.96$ at $95 \%$ confidence interval (CI). This gave a sample size of 382.95 pupils. Thus minimum sample size of 383 participants was expected for the study. Finally, due to their massive participation, 729 pupils were enrolled for this study.

$$
\mathrm{n}=\frac{\left(\mathrm{Z}_{1-\alpha / 2}\right)^{2} \cdot \mathrm{P}(1-\mathrm{P})}{d^{2}}
$$

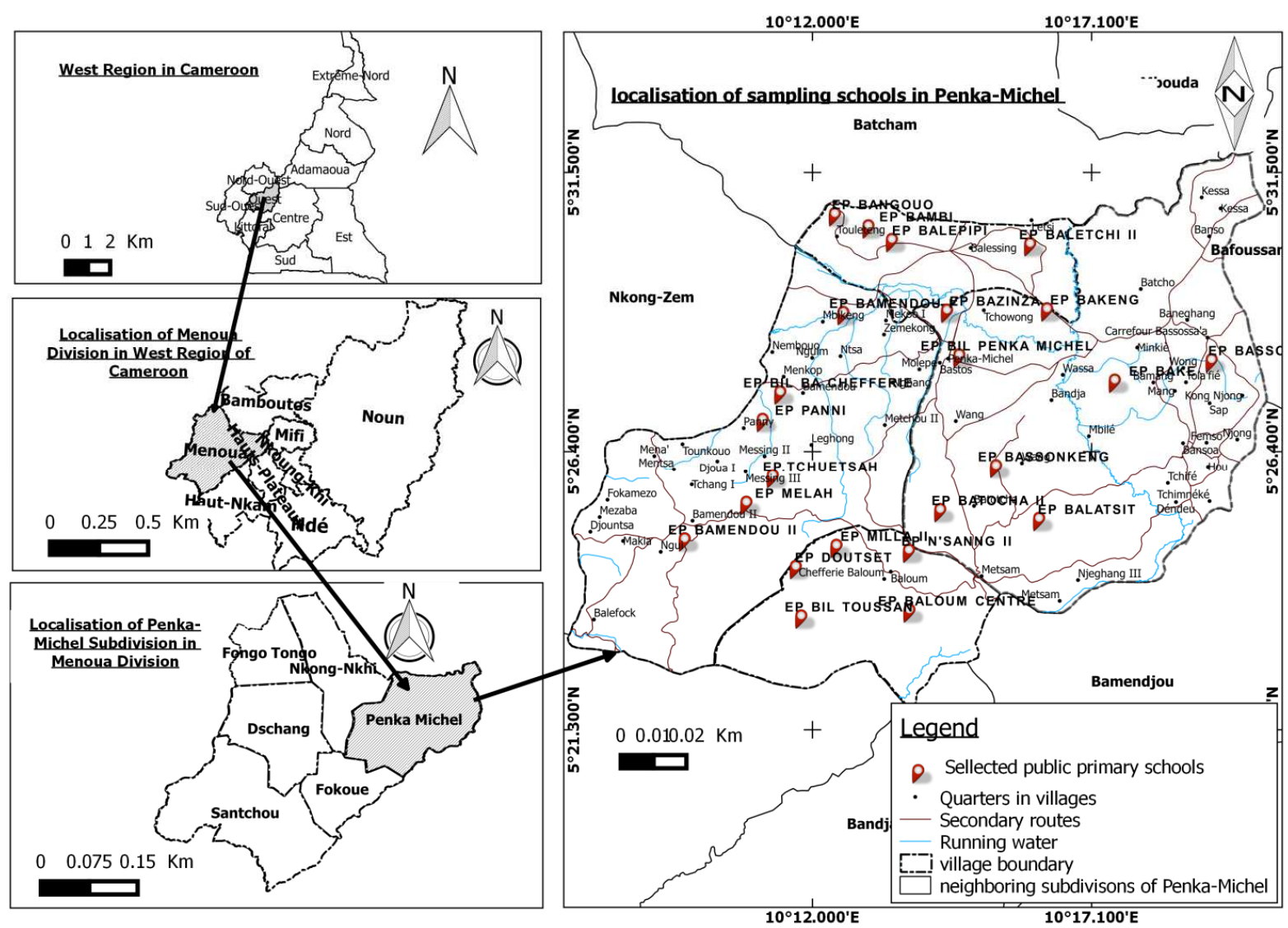

Figure 1. Study area and selected government primary schools in Penka-Michel Sub-subdivision.

\subsection{Scoring Hygienic Condition of the Selected Schools}

School's hygienic conditions were assessed through visual inspection [24]. This was done spontaneously during unannounced visits in selected schools. A total of 10 criteria were used to calculate the school hygienic score. For criteria with yes or no answer, a value of 1 or 0 was assigned respectively. For criteria with three possible outcomes, a value of 0.5 was assigned to the intermediate outcome. Once the score was calculated, the variable was dichotomized using an arbitrary cut-off value of 6.0. Schools scoring below 6 were categorized as with low hygienic level.

\subsection{Soil Sample Collection and Analysis for the Detection of STH Eggs}

Five hundred and fifty-two (552) soil samples were collected from September 2019 to February 2020 in the randomly selected 23 primary schools. Once in these schools, quadrate (Systematic unaligned sampling) or transect (Walking path transect sampling) was drawn at random on the selected sites and trowel was used to collect approximately $100 \mathrm{~g}$ of soil at a depth of $2-3 \mathrm{~cm}$ of topsoil from each quadrat or transect area $[25,26,1]$. Quadruplicate topsoil samples were taken from three ecologically relevant spots in the school. These were the playgrounds, classrooms backyards and toilets surroundings or defecation sites. Samples were kept in polythene bags, tied, and well labeled, then taken to the Research Unit of Applied Biology and Ecology (RUBEA) of the University of Dschang for analysis.

The soil samples were analyzed using the sucrose floatation technique as described by Uga et al. [27]. In the laboratory, each soil sample was sieved with a $150 \mu \mathrm{m}$ sieve to remove 
large particles. Two grams of powder were weighed and put in a test tube and mixed with $8 \mathrm{ml}$ of distilled water. After centrifugation at $1000 \mathrm{rpm}$ for $5 \mathrm{~min}$, the supernatant was discarded and the pellet rediluted with $8 \mathrm{ml}$ of sucrose solution (1.20). The mixture was vigorously shaken and centrifuged at $2000 \mathrm{rpm}$ for $10 \mathrm{~min}$. Finally, the interface and the upper layer obtained were collected and introduced into 3 test tubes until the formation of the upper meniscus. Three cover slips were carefully placed above the tubes. After 10 minutes, cover slips were removed carefully and placed on 3 slides and observed microscopically at 10x and 40x. The identification of eggs was done using morphological and morphometrical characteristics such as the size, shape, nature of the shell and the egg contents $[28,29]$. The number of eggs per gram of soil was calculated from the equation $\mathrm{N}=\mathrm{A} . \mathrm{X} / \mathrm{P} . \mathrm{M}$ where $\mathrm{A}$ is the mean counts from the slides, $\mathrm{X}$ the volume of the final product $(\mathrm{ml}), \mathrm{P}$ the estimated meniscus volume $(\mathrm{ml})$ and $\mathrm{M}$ the mass of the initial sample (2 g).

\subsection{Statistical Analysis}

Data were stored in Microsoft Excel Spread Sheet 2007 and analyzed using Statistical Package for Social Sciences (SPSS) version 22 and MedCalc online version 14.8.1 statistic software. Descriptive analysis was performed on the data and the results presented in tables and graphs. Statistical tests were carried out at $95 \%$ confidence interval. The data was tested for normality using the Kolmogorov-Smirnov test. Mean parasite egg densities of soil sampling sites were compared using non-parametric Kruskal-Wallis test $(\mathrm{H})$ or the Mann-Whitney $\mathrm{U}$ test (W) as seen appropriate. Chi square $\left(\chi^{2}\right)$ test was used to compare soil contamination rate.

Table 1. Demographic characteristics of pupil subjected to KAP surveys for soil transmitted helminthes.

\begin{tabular}{lll}
\hline Variable & Categories & Frequency (\%) \\
\hline \multirow{2}{*}{ Sex } & Male & $382(52.4)$ \\
& Female & $347(47.6)$ \\
\multirow{2}{*}{ Age (years) } & $4-7$ & $175(24.0)$ \\
& $8-11$ & $499(68.4)$ \\
& $12-14$ & $55(7.5)$ \\
\hline
\end{tabular}

\section{Results}

\subsection{Demographic Characteristics of Respondents}

All the 23 government primary schools selected participate in the study. In these schools, a total of 729 willing pupils (382 (52.4\%) boys and 347 (47.6\%) girls) participated in the study in the four villages of Penka-Michel Subdivision. The highest $(68.4 \%)$ and lowest $(7.5 \%)$ proportion of respondents were within the age range of 8-11 years and 12-14 years respectively. While a quarter $(24 \%)$ were aged 4 to 7 years (Table 1).

\subsection{Awareness Status of STH Among Respondents}

Approximately $44.3 \%$ of enrolled pupils have knowledge of parasitic worms. However, $85.6 \%$ do not actually know how to avoid getting infected with worms (Table 2). A large proportion of the respondents $(83.7 \%)$ indicated that they occasionally received anti-helminthic drugs. A total of 325 (44.6\%) walk barefooted while $48.1 \%$ of the respondents kept cat, pig and dog as pet animals. Their main source of drinking water was stream $(81.2 \%)$ followed by bore hole water $(16.0 \%)$. Some of the enrolled pupils used pit toilet (34.0\%) and also a large proportion (49.7\%) do not actually wash their hands after defecating/before eating or wash of fruits/vegetables before eating. Pupil's nails were mostly untrimmed $(74.1 \%)$ while $77.1 \%$ affirm always defecate out of the toilets when they are in school.

Table 2. Pupil's knowledge, attitude and practices towards STH infection.

\begin{tabular}{|c|c|c|c|}
\hline Parameters & Frequency (\%) & $\chi^{2}$ & P-value \\
\hline Knowledge on STH & & 9.340 & 0.002 \\
\hline Yes & $323(44.3)$ & & \\
\hline No & $406(55.7)$ & & \\
\hline prevention of STH & & 244.934 & $<0.001$ \\
\hline Yes & $105(14.4)$ & & \\
\hline No & $624(85.6)$ & & \\
\hline Deworming Frequency & & 227.590 & $<0.001$ \\
\hline Regular & $119(16.3)$ & & \\
\hline Occasionally & $610(83.7)$ & & \\
\hline $\begin{array}{l}\text { Source of drinking water at } \\
\text { home }\end{array}$ & & 771.218 & $<0.001$ \\
\hline Well & $20(2.7)$ & & \\
\hline Boring & $117(16.0)$ & & \\
\hline Stream & $592(81.2)$ & & \\
\hline Type of toilet at home & & 472.255 & $<0.001$ \\
\hline Absent & $1(0.1)$ & & \\
\hline Pittoilet & $248(34.0)$ & & \\
\hline Latrine & $480(65.8)$ & & \\
\hline Ownership of pets/animals & & 1.050 & 0.305 \\
\hline No & $378(51.9)$ & & \\
\hline Yes & $351(48.1)$ & & \\
\hline Walking barefooted & & 42.172 & $<0.001$ \\
\hline No & $193(26.5)$ & & \\
\hline Sometimes & $211(28.9)$ & & \\
\hline Always & $325(44.6)$ & & \\
\hline \multicolumn{2}{|c|}{ Hand washing after defecating/before eating } & 221.209 & $<0.001$ \\
\hline No & $311(42.7)$ & & \\
\hline Sometimes & $362(49.7)$ & & \\
\hline Always & $56(7.7)$ & & \\
\hline \multicolumn{2}{|c|}{ washing of fruits/vegetables before eating } & 95.366 & $<0.001$ \\
\hline Always & $197(27.0)$ & & \\
\hline Sometimes & $166(22.8)$ & & \\
\hline No & $366(50.2)$ & & \\
\hline Nail biting & & 137.319 & $<0.001$ \\
\hline Trimmed & $189(25.9)$ & & \\
\hline Untrimmed & $540(74.1)$ & & \\
\hline Open defecation & & 628.172 & $<0.001$ \\
\hline No & $85(11.7)$ & & \\
\hline Sometimes & $82(11.2)$ & & \\
\hline Always & $562(77.1)$ & & \\
\hline
\end{tabular}

\subsection{Soil Transmitted Helminths and Their Contamination Rate and Concentration Levels}

Out of 552 soil samples examined, 97 (17.6\%) were contaminated with at least one or more soil transmitted nematode eggs. These eggs were identified to the genera Ascaris, Trichuris, Capillaria, Toxocara, Cooperia, Nematodirus and hookworms (Table 3). Those of the genus 
Ascaris and Trichuris were the most frequent followed by the genera Toxocara and Capillaria. The average concentration of these eggs in soil samples expressed in terms of eggs per gram of soil (mean \pm standard deviation) also varied from one genus to another. High concentrations of eggs in soil were recorded with Ascaris sp $(15.01 \pm 14.97)$, Toxocara sp (8.75 \pm 3.03$)$, Trichuris sp $(8.40 \pm 3.79)$ and Capillaria sp $(7.18 \pm 2.56)$.

Table 3. Soil contamination rate and concentration levels of soil transmitted eggs in soil samples in selected primary schools during survey.

\begin{tabular}{|c|c|c|c|c|}
\hline $\begin{array}{l}\text { Soil transmitted } \\
\text { helminthes }\end{array}$ & $\begin{array}{l}\text { Number of soil } \\
\text { sample examined } \\
\end{array}$ & $\begin{array}{l}\text { Number of positive soil } \\
\text { sample }\end{array}$ & Contamination rate $(\%)$ & $\begin{array}{l}\text { Soil egg concentration } \pm \text { SD } \\
\text { eggs/g of soil }\end{array}$ \\
\hline Ascaris sp & 552 & 49 & 8.9 & $15.01 \pm 14.97$ \\
\hline Trichuris sp & 552 & 24 & 4.3 & $8.40 \pm 3.79$ \\
\hline Toxocara sp & 552 & 14 & 2.5 & $8.75 \pm 3.03$ \\
\hline Capillaria sp & 552 & 13 & 2.4 & $7.18 \pm 2.56$ \\
\hline Cooperia sp & 552 & 2 & 0.4 & 5.83 \\
\hline Hookworm & 552 & 1 & 0.2 & 5.83 \\
\hline Nematodirus sp & 552 & 1 & 0.2 & 5.83 \\
\hline
\end{tabular}

\subsection{Village - Related Soil Contamination Among Selected Government Primary School}

Four groups of schools literally stand out in the 4 villages surveyed (Figure 2). The first group consists of schools free of soil-transmitted helminth eggs. These include Balepipi and Bambi government primary schools in Balessing and PenkaMichel government bilingual school in Bansoa. The second group consists of schools which presented only one genus of soil-transmitted helminth eggs, those of Toxocara sp, Ascaris sp, Trichuris sp and Ascaris sp observed in Bangouo government primary schools in Balessing and Bamendou I in Bamendou and the Bake and Blatsit government schools in Bansoa respectively. The third group is made up of schools with significant diversity of soil-helminth egg genera. This is the case of Baletchi II and of Bazinza government primary schools in Balessing, Milla II and Doutset government primary schools in Baloum, Melah and Bamendou chiefdom government bilingual primary school, Bassonkeng and Batocha government primary schools in Bansoa. The fourth group is made up of schools whose soil contamination rate by certain type of nematode genera eggs was higher than the general contamination rate $(17.6 \%)$. These include not only Ascaris sp with $20.8 \%, 25 \%$ and $25 \%$ recorded in Baletchi II in Balessing, Melah in Bamendou and Baloum center government primary schools respectively, but also Toxocara sp eggs with $29.2 \%$ in Tcheutsah government primary school in Bamendou. In addition, irrespective of the village, eggs of the genus Ascaris were more frequent except in Tcheutsah, Milla II and Batocha I government primary schools.
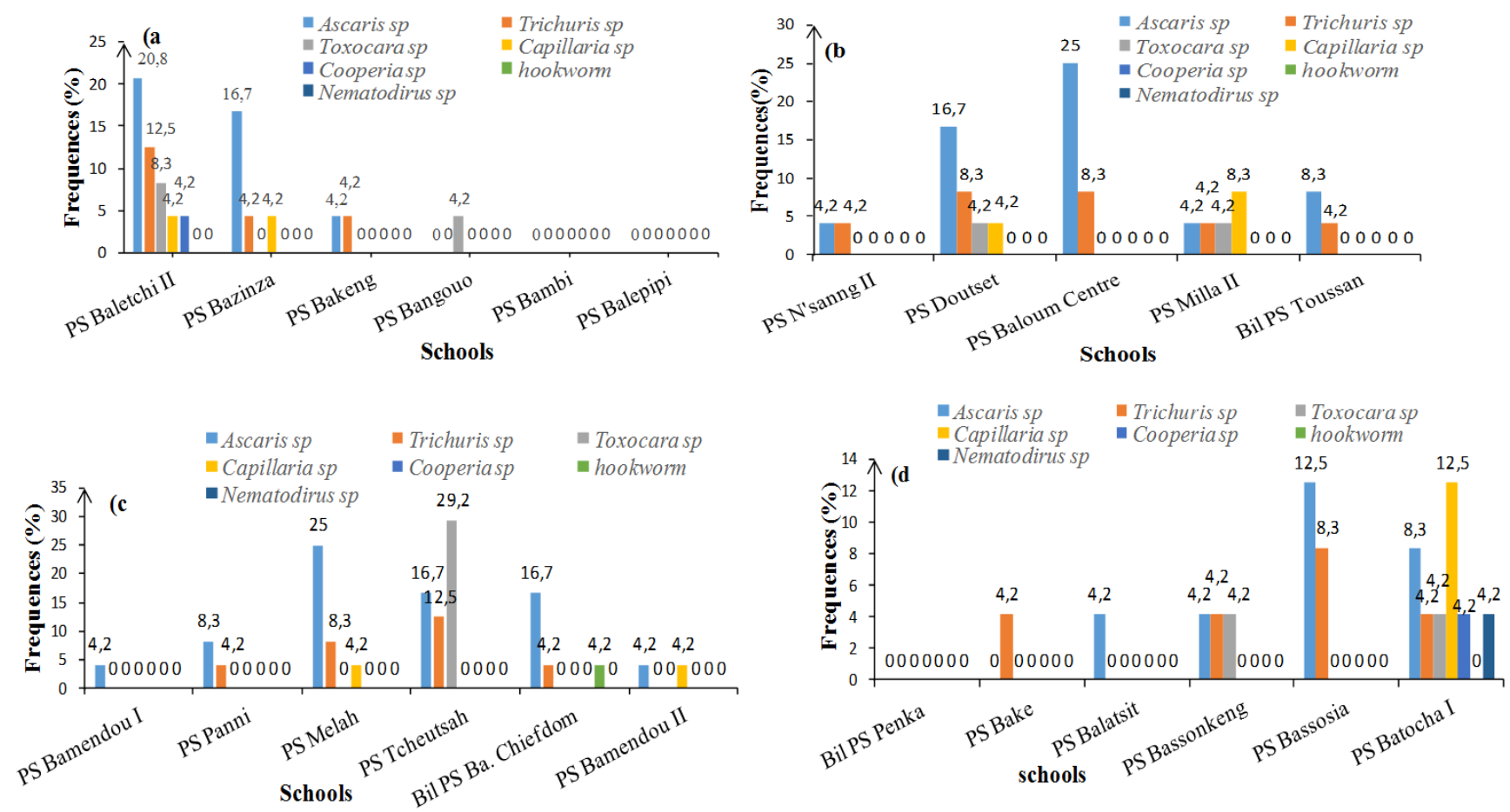

Figure 2. Distribution of soil transmitted nematode genera among government primary schools: a) Balessing, b) Baloum, c) Bamendou and d) Bansoa. 


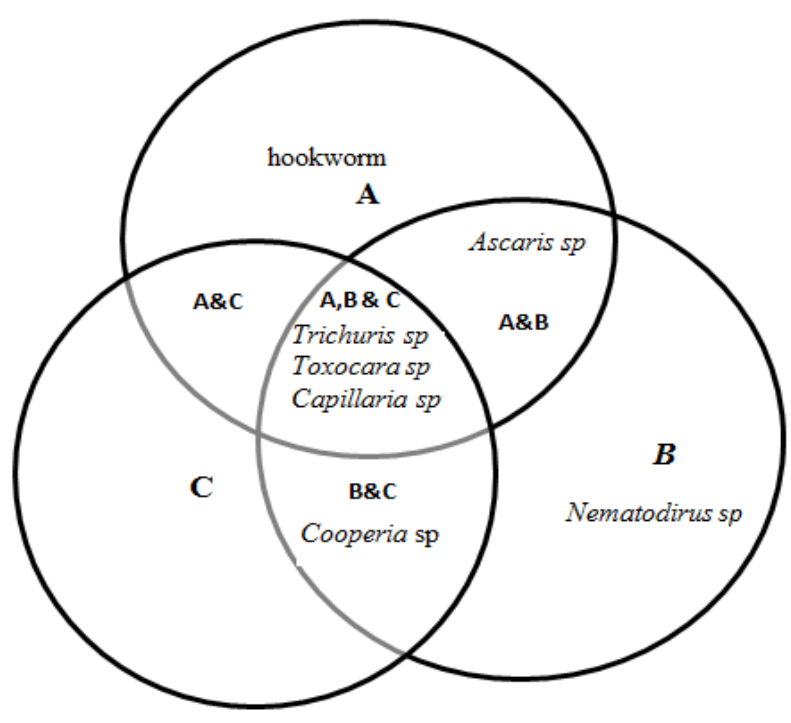

Figure 3. Distribution of identified soil transmitted helminth eggs among the sample sites: $A=$ around toilets, $B=$ classroom backyards and $C=$ playgrounds.

\subsection{Distribution of Soil Transmitted Nematodes Among the Soil Sampling Sites}

The nematode eggs identified were not uniformly distributed among the three soil sampling sites (Figure 3).
This diagram reveals three very different ecological groupings based on their geohelminth egg composition: groups A and B potentially rich and specific to hookworm and Nematodirus sp egg respectively; The sharing groups $\mathrm{A} \& \mathrm{~B}$ and $\mathrm{B} \& \mathrm{C}$ potentially rich and specific to Ascaris sp and Cooperia sp eggs respectively; group $\mathrm{C}$ and sharing groups A\&C rich but devoid of specificity in type of helminth egg.

\subsection{Site - Related Contamination Rate and Soil Concentration of Soil-transmitted Helminth Eggs in Soil Samples}

The contamination rate and soil concentration of soiltransmitted helminth eggs varied among the three sampling sites (table 4). It appears that the contamination rate from around toilets was significantly $(\mathrm{p}<0.001)$ higher $(12.3 \%)$, than that from classroom backyards $(3.8 \%)$ and that from playgrounds (1.4\%). Ascaris sp (7.8\%) and Trichuris sp $(3.6 \%)$ eggs were significantly $(\mathrm{P}<0.001)$ more frequent around toilets than to classrooms backyards and in pupil playgrounds. Indeed, average concentration of identified eggs did not vary significantly $(\mathrm{P}>0.05)$ between contaminated soil samples from one site to another.

Table 4. Variation of contamination rate and soil concentration of soil-transmitted helminth eggs among soil sampling sites.

\begin{tabular}{|c|c|c|c|c|c|c|c|c|c|}
\hline \multirow[b]{3}{*}{ parasites } & \multirow{2}{*}{\multicolumn{2}{|c|}{ Around toilets }} & \multicolumn{7}{|l|}{ Sites } \\
\hline & & & \multicolumn{2}{|c|}{ Classroom backyards } & \multicolumn{5}{|c|}{ Playground } \\
\hline & $\begin{array}{c}{ }^{1} \text { C. } \mathbf{R} \\
\text { N }(\%)\end{array}$ & $\begin{array}{l}{ }^{2} \text { S. E. C } \\
\text { egg/g of soil }\end{array}$ & $\begin{array}{l}\text { C. R } \\
\text { N (\%) }\end{array}$ & $\begin{array}{l}\text { S. E. C } \\
\text { egg/g of soil }\end{array}$ & $\begin{array}{l}\text { C. R } \\
\text { N }(\%)\end{array}$ & $\begin{array}{l}\text { S. E. C } \\
\text { egg/g of soil }\end{array}$ & $\begin{array}{l}\text { Total } \\
\text { N (\%) }\end{array}$ & $\begin{array}{l}\text { C. R } \\
\text { P-value }\end{array}$ & $\begin{array}{l}\text { S. E. C } \\
\text { P-value }\end{array}$ \\
\hline Ascaris $\mathrm{sp}$ & $43(7.8)^{\mathrm{a}}$ & $15.74 \pm 15.82$ & $6(1.1)^{b}$ & $9.72 \pm 3.01$ & $0(0,0)^{b}$ & - & $49(8.9)$ & 0.001 & 0.361 \\
\hline Trichuris sp & $20(3.6)^{\mathrm{a}}$ & $8.61 \pm 3.96$ & $3(0.5)^{\mathrm{b}}$ & $5.83 \pm 00$ & $1(0.2)^{b}$ & 11.67 & $24(4.3)$ & 0.001 & 0.261 \\
\hline Toxocara sp & $4(0.7)^{a}$ & $9.72 \pm 3.37$ & $7(1.3)^{\mathrm{a}}$ & $8.33 \pm 3.12$ & $3(0.5)^{\mathrm{a}}$ & $8.75 \pm 3.37$ & $14(2.5)$ & 0.395 & 0.820 \\
\hline Capillaria sp & $5(0.9)^{\mathrm{a}}$ & $5.83 \pm 00$ & $4(0.7)^{\mathrm{a}}$ & $7.29 \pm 2.92$ & $4(0.7)^{\mathrm{a}}$ & $8.75 \pm 3.37$ & $13(2.4)$ & 0.926 & 0.235 \\
\hline ankylostomes & $1(0.2)$ & 5.83 & $0(0.0)$ & - & $0(0.0)$ & - & $1(0.2)$ & 0.367 & - \\
\hline Nematodirus sp & $0(0.0)$ & - & $0(0.0)$ & - & $1(0.2)$ & 5.83 & $1(0.2)$ & 0.367 & - \\
\hline Total & $68(12.3)^{\mathrm{a}}$ & & $21(3.8)^{\mathrm{b}}$ & & $8(1.4)^{\mathrm{c}}$ & & $97(17.6)$ & .000 & \\
\hline
\end{tabular}

${ }^{1} \mathrm{C} . \mathrm{R}=$ contamination rate, ${ }^{2} \mathrm{~S}$. E. $\mathrm{C}=$ Soil Egg Concentration

C. R P-value determination: $\mathrm{a}$ and $\mathrm{b}$ on the same line $=$ significant at $\mathrm{P}<0.05-\mathrm{a}$, a on the same line $=$ non-significant at $\mathrm{P}>0.05-\mathrm{a}, \mathrm{b}$ and $\mathrm{c}$ on the same line $=$ significant at $\mathrm{P}<0.05$

S. E. C P-value determination: no symbols on the same line $=$ non-significant at $\mathrm{P}>0.05$

\subsection{Hygienic Scores of Various Primary Schools Sampled}

The average hygienic score of sampled schools in the 4 villages were below 6 and therefore low level of hygiene (Table 5). Water and sink facilities whether functional or not were the most absent in these schools. Two types of toilets occurred: the latrines (commonly observed) and the pits. Although present, these health facilities were non-functional in 6 of the 23 schools inspected. The unhealthy surroundings and in the toilets accompanied by fragrant odors from the piles of feces and urine frequently noted in most of these schools strongly impacted their hygienic level. The complete absence of school perimeter fence in many schools give chance to animals to access the schools.

\subsection{Predicting Factors Associated to Soil Contamination by Soil-Transmitted Helminth and Risk of Pupils Infection}

Soil contamination in selected schools was significantly $(\mathrm{P}<0.001)$ related to sampling sites, the number of pupil enrolled in school, the absence of water during class time, number of toilet, lack of clean toilets both inside and outside, odor control in toilets, absence of sink for hand washing and fence (Table 6). 
Table 5. Average hygienic scores in sampled primary schools.

\begin{tabular}{|c|c|c|c|c|c|c|}
\hline & Criteria & & & & & \\
\hline Villages & $\begin{array}{l}\text { Water during } \\
\text { class hours }^{\mathrm{a}}\end{array}$ & $\begin{array}{l}\text { Sink with water for } \\
\text { handwashing }^{\mathrm{b}}\end{array}$ & $\begin{array}{l}\text { Clean surroundings } \\
\text { classroom area }\end{array}$ & $\begin{array}{l}\text { Type of } \\
\text { toilets }^{c}\end{array}$ & $\begin{array}{l}\text { Sanitary facilities } \\
\text { funtional }\end{array}$ & $\begin{array}{l}\text { Clean surrounding } \\
\text { toilets areas }\end{array}$ \\
\hline Baloum & 0.1 & 0.00 & 0.60 & 0.90 & 0.60 & 0.20 \\
\hline Bamendou & 0.33 & 0.00 & 0.83 & 0.83 & 0.67 & 0.33 \\
\hline Balessing & 0.25 & 0.00 & 0.83 & 1.00 & 0.83 & 0.50 \\
\hline Bansoa & 0.42 & 0.25 & 0.50 & 1.00 & 0.67 & 0.50 \\
\hline
\end{tabular}

Table 5. Continued.

\begin{tabular}{|c|c|c|c|c|c|c|}
\hline & Criteria & & & & & \\
\hline Villages & $\begin{array}{l}\text { Inside toilet } \\
\text { clean }\end{array}$ & $\begin{array}{l}\text { Control of toilet } \\
\text { odours }^{\mathrm{d}}\end{array}$ & $\begin{array}{l}\text { School perimeter } \\
\text { fence }^{\mathrm{e}}\end{array}$ & $\begin{array}{l}\text { Animal imprints in } \\
\text { school environment }\end{array}$ & $\begin{array}{l}\text { Average hygienic } \\
\text { score }\end{array}$ & Average hygienic level \\
\hline Baloum & 0.20 & 0.30 & 0.00 & 0.60 & 3.50 & low \\
\hline Bamendou & 0.33 & 0.33 & 0.08 & 0.33 & 4.08 & low \\
\hline Balessing & 0.33 & 0.33 & 0.17 & 0.83 & 5.10 & low \\
\hline Bansoa & 0.67 & 0.33 & 0.17 & 0.50 & 5.00 & low \\
\hline
\end{tabular}

${ }^{\mathrm{a}}$ tape and water; only tape but no water $=0,5 ;{ }^{\mathrm{b}} \operatorname{Sink}$ and water $=1$; only sink but no water available $=0.5$

$\mathrm{C}_{\text {latrine }}=1$; flush toilets $=0,5 ;$ dodourless $=1$, less fragrant $=0,5 ;{ }^{\text {e }}$ fence with: definitive material $=1$; local material $=0,5$

Table 6. Predicting factors associated to soil contamination and risk of pupil's infection.

\begin{tabular}{|c|c|c|c|c|c|}
\hline Variables & $\mathbf{N}$ & Frequency n (\%)* & odd ratio & $95 \% \mathrm{CI}$ & P-value \\
\hline \multicolumn{6}{|l|}{ Sampling sites } \\
\hline Playground & 184 & $8(1.4)^{b}$ & 1.00 & & - \\
\hline Behind classroom & 184 & $21(3.8)^{b}$ & 0.35 & {$[0.15-0.82]$} & 0.015 \\
\hline Around toilets & 184 & $68(12.3)^{\mathrm{a}}$ & 0.07 & {$[0.04-0.17]$} & $<0.001$ \\
\hline \multicolumn{6}{|c|}{ Number of student enrolled } \\
\hline$[100-250]$ & 144 & $24(4.4)^{\mathrm{a}, \mathrm{b}}$ & 1.00 & & - \\
\hline [250-400] & 216 & $47(8.5)^{\mathrm{b}}$ & 0.71 & {$[0.42-1.24]$} & 0.235 \\
\hline$>400$ & 192 & $26(4.7)^{\mathrm{a}}$ & 1.27 & {$[0.69-2.33]$} & 0.426 \\
\hline \multicolumn{6}{|c|}{ Water during class hours } \\
\hline No & 456 & $81(14.7)^{\mathrm{a}}$ & 1.00 & & - \\
\hline yes & 96 & $16(2.9)^{\mathrm{b}}$ & 1.08 & {$[0.59-1.94]$} & 0.797 \\
\hline \multicolumn{6}{|l|}{ Type of toilets } \\
\hline Pit toilets & 48 & $22(3.9)^{b}$ & 1.00 & & - \\
\hline latrine & 504 & $75(13.6)^{\mathrm{a}}$ & 4.84 & {$[2.60-8.98]$} & $<0.001$ \\
\hline \multicolumn{6}{|c|}{ Functionality of Sanitary facilities } \\
\hline No & 168 & $48(8.7)^{\mathrm{a}}$ & 1.00 & & - \\
\hline yes & 384 & $49(8.9)^{\mathrm{a}}$ & 2.73 & {$[1.74-4.28]$} & $<0.001$ \\
\hline \multicolumn{6}{|l|}{ Number of toilets } \\
\hline [01-02] & 384 & $89(16.1)^{\mathrm{a}}$ & 1.00 & & - \\
\hline [03-05] & 120 & $3(0.5)^{\mathrm{b}}$ & 11.76 & {$[3.65-37.92]$} & $<0.001$ \\
\hline$\geq 06$ & 48 & $5(0.9)^{\mathrm{b}}$ & 0.30 & {$[0.08-1.06]$} & 0.062 \\
\hline \multicolumn{6}{|c|}{ Clean surrounding and inside toilets areas } \\
\hline No & 360 & $86(15.6)^{\mathrm{a}}$ & 1.00 & & - \\
\hline yes & 192 & $11(1.9)^{\mathrm{b}}$ & 5.16 & {$[2.68-9.94]$} & $<0.001$ \\
\hline \multicolumn{3}{|c|}{ Control of odour in toilet } & 1.00 & & - \\
\hline less fragrant & 168 & $18(3.3)^{\mathrm{b}}$ & 0.41 & {$[0.17-0.98]$} & 0.046 \\
\hline fragrant & 216 & $71(12.9)^{\mathrm{c}}$ & 0.10 & {$[0.05-0.22]$} & $<0.001$ \\
\hline \multicolumn{6}{|l|}{ Sink? } \\
\hline No & 480 & $89(16.1)^{\mathrm{a}}$ & 1.00 & & - \\
\hline yes & 72 & $8(1.4)^{b}$ & 1.82 & {$[0.84-3.93]$} & 0.127 \\
\hline \multicolumn{6}{|l|}{ Gate } \\
\hline No & 456 & $84(15.2)^{\mathrm{a}}$ & 1.00 & & - \\
\hline Local material & 96 & $13(2.4)^{\mathrm{b}}$ & 1.44 & {$[0.77-2.71]$} & 0.255 \\
\hline
\end{tabular}

$\mathrm{a}$ and $\mathrm{b}$ on the same column=significant at $\mathrm{P}<0.05-\mathrm{a}$, a on the same column=non-significant at $\mathrm{P}>0.05$

$\mathrm{a}, \mathrm{b}$ and $\mathrm{c}$ on the same column=significant at $\mathrm{P}<0.05 .{ }^{*}$ contaminated soil samples

Among these factors, the best predicting determinant factors associated to soil contamination by STH in schools were the type of toilets, the functionality of these toilets, the lack of clean toilets, and the odour control in toilets. So pupils were at 4.84 [2.60 - 8.98] times exposed to STH infection in school with pit toilets $(\mathrm{p}<0.0001), 2.73$ [1.74 4.28] exposed in schools with no functional toilets $(\mathrm{p}<$ $0.0001), 11.76$ [3.65 - 37.92] and 0.30 [0.08 -1.06] times exposed in schools with 1-2 toilet as compared to those schooled in school with $3-5$ and $\geq 06$ toilets respectively. 
They were also exposed at 5.16 [2.68-9.94] times to STH infection in school with lack of cleaning surrounding and inside toilets areas $(\mathrm{p}<0.0001)$.

\section{Discussion}

The present study demonstrated that a reasonable proportion of pupils had inadequate level of knowledge on STHs aetiology. As far as preventive methods, attitude and practices are concerned, up to $80 \%$ of pupils were unable to provide correct answers regarding STH transmission and prevention. This result may be the consequence of misconception of their parent or tutor on STH transmission and prevention as mentioned by [30]. Another misconception can derive from poor basic health educational background on transmission, and prevention of infections teaches in school. These misconceptions and beliefs further undergird the need for comprehensive health education interventions as integral components of STH control in these settings [31].

The overall rate of soil contamination $(17.6 \%)$ by STH eggs obtained in the present study could be as a result of poor environmental sanitation and poor hygiene habits, reflecting the pupil's behaviour regarding environmental cleanliness and the negligence of this issue by the school staff. Pupils are unaware of environmental contamination risks. So the presence of potentially pathogenic helminth parasites in the school environment exposes pupils to infection. This result was higher than the $7.75 \%$ reported by Nkouayep et al. [32] in ten primary schools in Dschang, West Cameroon. But less than $26.79 \%$ obtained by Ntonifor et al. [33] in the Upper Nkongho-mbo Area, South-west Region, Cameroon.

All the STH eggs identified were potential cause of zoonotic diseases except one (Nematodirus sp). Ascaris sp, Trichuris sp and hookworm which have been previously reported elsewhere [32, 13, 34] are of public health importance. Toxocara sp, Capillaria sp, Cooperia sp and Nematodirus sp are of animal origin. Capillaria $\mathrm{sp}$ and Cooperia sp were previously reported by Nkouayep et al. [32], Toxocara sp by Obaid, [35] in other school environments. Nematodirus sp are reported here for the first time. The diversity of these STH eggs identified in the present study underlines the low hygienic level frequently observed in the primary schools. This may be due to: 1) the indiscriminate open defecation habits of pupils; 2) lack of perimeter fence which probably favors the presence of large numbers of stray animals (dogs, cats, rodents and ruminants) roaming in these schools.

The presence and survival of nematode eggs in the soil are mostly related to environmental climatic condition and soil characteristics [1]. The rate of soil contamination was the same among villages but significant difference $(p<0.05)$ was obtained among selected schools. It was interesting to observe that floors in some schools were free of STH eggs. This could be the consequence of good practice of hygienic rules by school children under the supervision of teaching staff. Another reason could be the topography of these schools, because placed on a hillside, runoff water could participate during the rainy season in leaching the soil and thereby cause the STH eggs away from the school site.

Irrespective of village and school, Ascaris sp eggs were the most common and predominant among the seven genera of nematode eggs identified. This is in line earlier reports elsewhere $[33,32,13]$ and may be explained by the fact that Ascaris eggs are resistant to harsh environmental conditions and are laid in rather large numbers given the high fecundity of Ascaris (200.000 eggs/day/female) [29] and their high prevalence among pupils [4]. The scanty occurrence of Cooperia sp, Nematodirus sp and hookworms eggs may be explained by their life cycle and infective form. Once in the environment they quickly hatch into larvae in normal climatic condition within few days or weeks [29].

Contamination rate was highest around toilet area (12.3\%) followed by classroom backyards $(3.8 \%)$. This may be as result of the seclusion of toilets whose unhygienic condition drove pupils to defecate behind classrooms or in surrounding bushes. This open communal contamination of soil with infected faeces thus poses a serious risk to uninfected pupils and also serves as a source of re-infection [34]. In fact, in schools lacking functional toilet facilities, pupils are at high risk of contracting more than one STH species. Ascaris sp and Trichuris $\mathrm{sp}$ eggs were significantly $(\mathrm{P}<0.001)$ more common around toilets. This is in agreement with the findings of Omotola, [19] in Nigeria and Nkouayep et al. [32] in Cameroon. It seems clear that instead of using toilets some pupils usually defecate around/behind toilets and behind classrooms.

The hygienic level of schools was generally low, in this study could promote fecal contamination of school environment with helminth eggs from infected pupils or stray animals [12].

Almost all hygienic criteria considered were highly related to soil contamination except the type and functionality of toilet. Among these criteria all those related to unhygienic condition of toilet were identified as important predictors of STH infection. So Contamination of the school environment with infective stages of STHs is considerable in the absence of adequate sanitation [36, 37].

\section{Limitations}

Enormous material and logistical efforts were made to collect the data for this study. We are really satisfied with the relevant results obtained because they fill some gaps in knowledge of awareness status of pupils in the selected public primary schools in Penka-Michel on transmission and prevention of STH and soil contamination rates by STH in their school.

Collecting similar information's in households in relation to the perception of their parents or guardians will be considered in our future studies. This in order to reduce some limitations observed during the study. 


\section{Conclusion}

The high rate of soil contamination not only by human faeces but also by other animal faeces observed in the selected schools in the present study coupled with the high proportion of pupil with inadequate knowledge on how to prevent transmission of STH poses a high risk of STH infection in pupil. Therefore, there is a need for proper education on parasite transmission in public primary schools. We also recommend that there should be significant improvement in the sanitary/water facilities in public primary schools. Continuous education/enlightenment program that strongly emphasise strict compliance to personal and environmental hygiene should also be developed and implemented. Full identification of STH involved and their zoonotic nature should be investigated.

\section{Conflict of Interest}

The authors declare that they have no competing interests.

\section{Acknowledgements}

Special appreciation goes to the teaching staff of the schools involved in the study for granting to obtain soil sample from the school premises. We sincerely appreciate the support and cooperation of pupils and their hospitality. We wish to express our sincere thanks to all the members of the Research Unit of Biology and Applied Ecology (RUBAE) for their help during field and laboratory work.

Also, we thank the late Prof WABO PONE Josué, for his remarkable scientific criticism and encouragement.

\section{References}

[1] Hassan, A. A., Oyebamiji, D. A., (2018). Intensity of soil transmitted helminths in relation to soil profile in selected public schools in Ibadan metropolis. Journal of Epidemiology and Infectious Diseases, 1 (2): 73-77.

[2] Njiru, J. M., Muhoho, N., Simbauni, J. A., Kabiru, E., (2016). Effects of soil transmitted helminthes and Schistosoma species on nutritional status of children in Mwea Irrigation Scheme, Kenya. Journal of Applied Life Sciences International, 5 (1), 1-8.

[3] WHO (2018): Soil-transmitted helminth infections. Retrieved 22 May, 2018, from http://www.who.int/news-room/factsheets/detail/ soil-transmitted-helminth-infections.

[4] Atiokeng Tatang, R. J., Yondo, J., Nguemfo Tchankugni, A., Nkouayep, V. and Mpoame Mbida (2020). Soil-Transmitted Helminths: Prevalence and Intensity of Some Soil Transmitted Nematodes among Pupils in Selected Primary Schools in PenkaMichel Sub-division, West-Cameroon. International Journal of Tropical Disease \& Health; 41 (6): 11-22.

[5] WHO (2012): Research priorities for helminth infections: technical report of the TDR disease reference group on helminth infections. Technical report series; $\mathrm{n}^{\circ} 972$.

[6] Richardson, D. J., Richardson, K. R., Callahan, K. D., Gross, J., Tsekeng, P., Dondji, B., et al (2011). Geoheminth infection in rural Cameroonian villages. Comparative Parasitololy, 78: 161-79.

[7] Omotola, O. A., Ofoezie, I. E (2019). Prevalence and intensity of soil transmitted helminthes among school children in Ifetedo, Osun State, Nigeria. Journal of Bacteriololgy and Parasitology, 10: 352-356.

[8] Masaku, J., Mwende, F., Odhiambo, G., Musuva, R., Matey, E., Kihara, J. H., et al. (2017). Knowledge, practices and perceptions of geo-helminthes infection among parents of preschool age children of coastal region, Kenya. PLoS Neglected Tropical Diseases, 11 (3): e0005514.

[9] Da Silva Alves, E. B., Conceição, M. J., Leles, D. (2016): Ascaris lumbricoides, Ascaris suum, or 'Ascaris lumbrisuum'? The Journal of Infectious Diseases. 213: 1355.

[10] Ma, G., Holland, C. V., Wang, T., Hofmann, A., Fan, C. K., Maizels, R. M. (2018). Human toxocariasis. Lancet Infectious Diseases, 18: e14-e24.

[11] Bowman, D. D., Montgomery, P. S., Zajac, M. A., Eberhard, L. M., Kazacos, R. K. Hookworms of dogs and cats as agents of cutaneous larva migrans. Trends in Parasitology 2010; 26: 162-167.

[12] Santarém, V. A., Guita, R-E. and Ferreira, M. U.). SoilTransmitted Helminthic Zoonoses in Humans and Associated Risk Factors, Soil Contamination. MSc Simone Pascucci 2011; p 45-66.

[13] Isaac C., Turay P. N., Inegbenosun C. U., Ezekiel S. A., Adamu H. O., Ohiolei J. A. Prevalence of soil-transmitted helminths in primary school playgrounds in Edo State, southern Nigeria. Helminthologia 2019, 56 (4): 282-295.

[14] Lloyd, E. A., Honey, L. B., John, M. B., Condrem, M. Treatment options and considerations for intestinal helminthic infections. Journal of Pharmacy Technology 2014; 30: 130139.

[15] Vandemark, L. M., Jia, T. W. and Zhou, X. N. "Social science implications for control of helminth infections in South East Asia". Advances in Parasitology 2010; 73: 137-170.

[16] Umeh C., Mbanugo J. I. and Ezeugoigwe, N. Prevalence of intestinal helminthes parasite in stools ofnursery and primary schools pupils in Uga, Anambra State, Nigeria. Sky Journal of Microbiology Research 2015; 3 (1): 006-010.

[17] Gyoten, J., Hoa, N., Fujimaki, Y., Tanaka, K., Uga, S. and Noda, S. The correlation between contamination of soil with Ascaris sp. eggs in school yards and ascariasis among primary school children in Mai Trung Commune, Northern Vietnam. Tropical Medicine and Health 2010; 38: 35-38.

[18] Horiuchi, S., Paller, V., and Uga, S. Soil contamination by parasite eggs in rural village in the Philippines. Tropical Biomedicine 2013; 30: 495-503.

[19] Omotola, O. A. Environmental geo-helminth contamination and prevalence of soil-transmitted helminths among school children in ifetedo. Thesis, Obafemi Awolowo University, osun state, Nigeria 2017, 127p.

[20] Grimes, J. E. T., Tadesse, G., Mekete, K., Wuletaw, Y., Gebretsadik, A., French, M. D., et al. School Water, Sanitation, and Hygiene, Soil-Transmitted Helminths, and Schistosomes: National Mapping in Ethiopia. PLoS Neglected Tropical Disease 2016, 10 (3): e0004515. 
[21] Tchuem Tchuenté L-A. Control of soiltransmitted helminths in sub-Saharan Africa: diagnosis, drug efficacy concerns and challenges. Acta Tropical 2011, 120 (1): 4-11.

[22] Kouitcheu Mabeku, L. B., Tchakounte, C., Tchuandom, B. S., Etoa, F. X. Prevalence of Toxoplasma gondiiand associated risk factors among pregnant women attending hospital centers in Penka-Michel, Cameroon. Journal of Scientific Research \& Reports 2018; 21 (2): 1-11.

[23] Tchuem Tchuenté L-A, Dongmo Noumedem C, Ngassam P, Kenfack CM, Feussom Gipwe N, Dankoni E, Tarini A, Zhang Y. Mapping of schistosomiasis and soil-transmitted helminthiasis in the regions of Littoral, North-West, South and South-West Cameroon and recommendations for treatment. BMC Infectious Diseases. 2013; 13: 602-613.

[24] Gabrie, J. A. Risk Factors for Soil-Transmitted Helminth Infections in Schoolchildren from Rural Communities in Honduras. Thesis, Faculty of Applied Health Sciences, Brock University 2013; 182p

[25] Collender, P. A., Kirby, A. E., Addiss, D. G., Freeman, M. C. and Remais, J. V. Methods for quantification of soiltransmitted helminths in environmental media: current techniques and recent advances Trends in Parasitology 2015; 31 (12): 625-639.

[26] Hassan, A. A., Oyebamiji, D. A., Idowu, O. F. Spatial patterns of soil transmitted helminths in soil environment around Ibadan, an endemic area in south-west Nigeria. Nigerian Journal of Parasitology 2017; 38 (2): 179-184.

[27] Uga, S. T., Matsumura, N., Aoki, and Kataoka, N. "Prevalence of Toxocara species eggs in the sandpits of public parks in Hyogo Prefecture, Japan," Japanese Journal of Parasitology 1993; 38 (5): 280-284

[28] Thienpont, D., Rochette, F., Vanparij, O. F. Diagnosis of verminosis by coprological examinations, Beerse, Belgium, Janssen Research Foundation 1979; 109p.

[29] Soulsby, E. J. F. Helminths, Arthropods and Protozoa of domesticated animals. 7th ed. London, United Kingdom: Bailliere Tindall 1982; 809p.

[30] Eze, P., Agu, U. J., Aniebo, C. L., Agu, S. A., and Lawani, L. O. Perception and attitudinal factors contributing to periodic deworming of preschool children in an urban slum, Nigeria. BMC Public Health 2020; 20: 1839.

[31] Sacolo-Gwebu H, Kabuyaya M, Chimbari M. Knowledge, attitudes and practices on schistosomiasis and soil-transmitted helminths among caregivers in Ingwavuma area in uMkhanyakude district, South Africa. BMC Infectious Diseases. 2019; 19 (1): 1-11.

[32] Oyebamiji, D. A., Ebisike, A. N., Egede, J. O., Hassan, A. A. Knowledge, attitude and practice with respect to soil contamination by soil-transmitted helminths in Ibadan, Southwestern Nigeria. Parasite and Epidemiology Control 2018; 3: e00075.

[33] Nkouayep, V. R., Tchakounté, B. N., Poné, J. W. Profile of geohelminth eggs, cysts, and oocysts of protozoans contaminating the soils of ten primary schools in Dschang, West Cameroon. Journal of Parasitology Research 2017, $1534675,6 \mathrm{p}$

[34] Ntonifor, N. G, Irene, N. S and Tabot, J. E. Soil-Transmitted Helminth Infections and Associated Risk Factors in a Neglected Region in the Upper Nkongho-mbo Area, Southwest Region, Cameroon. International Journal of Tropical Disease and Health 2016; 16 (3): 1-9.

[35] Obaid, H. M. Parasitic stages isolation from soil samples of Kirkuk Technical College. Annals of Mechnikov Institute 2019; 1: 12-16

[36] Hotez, P. J. One world health: Neglected tropical diseases in a flat world. PLoS Neglected Tropical Disease 2009; 3: 405.

[37] Ziegelbauer, K., Speich, B., Mausezahl, D., Bos, R., Keiser, J., Utzinger, J. Effect of sanitation on soil-transmitted helminth infection: Systematic review and metaanalysis. PLOS Medicine 2009, 9: e1001162. 